\title{
EVALUACIÓN DE LA ACTIVIDAD ANTIOXIDANTE DEL EXTRACTO HIDROALCOHÓLICO ESTANDARIZADO DE HOJAS DE Juglans neotropica Diels (NOGAL PERUANO)
}

\author{
Paola Hurtado Manrique *a, Bertha Jurado Teixeira a, Eva Ramos Llica a, María Calixto \\ Cotos $^{\mathrm{b}}$
}

\begin{abstract}
RESUMEN
Juglans neotropica Diels "nogal peruano" es un árbol que crece en ceja de selva, en zonas de bosque húmedo premontano y montano, cuyas hojas poseen propiedades antioxidante, astringente, antibacteriana y antiséptica. El objetivo fue evaluar la actividad antioxidante del extracto hidroalcohólico estandarizado de las hojas de Juglans neotropica Diels. Se usó hojas provenientes del distrito de Huandoval, provincia de Pallasca, Región Ancash. El análisis de estandarización comprendió determinación de humedad, parámetros fisicoquímicos, marcha de solubilidad, tamizaje fitoquímico y cromatografía en capa fina; la actividad antioxidante fue determinada por el ensayo de inhibición de DPPH. En tamizaje fitoquímico hubo mayor concentración de compuestos fenólicos y la actividad antioxidante se presentó a 25 y $35 \mu \mathrm{g} /$ $\mathrm{mL}$, respectivamente, con un IC 50 de 12,82 $\mu \mathrm{g} / \mathrm{mL}$. En conclusión, el extracto hidroalcohólico estandarizado de hojas de Juglans neotropica Diels cumplió con los parámetros de calidad, presentando alta actividad antioxidante.
\end{abstract}

Palabras clave: Juglans neotropica Diels, nogal peruano, extracto estandarizado, tamizaje fitoquímico, actividad antioxidante.

\section{EVALUATION OF ANTIOXIDANT ACTIVITY OF THE STANDARDIZED HYDROALCOHOLIC EXTRACT FROM Juglans neotropica Diels (PERUVIAN WALNUT) LEAVES}

\begin{abstract}
Juglans neotropica Diels "peruvian walnut" is a tree that grows in jungle, in areas of montane and montane rain forest whose leaves have antioxidant, astringent, antibacterial and antiseptic properties. The objective was to determine the antioxidant activity of a standardized hydroalcoholic extract of Juglans neotropica Diels leaves. Leaves from Huandoval district, Pallasca province, Ancash Region were used. Standardization analysis included determination of moisture, physicochemical parameters, solubility march, phytochemical screening, and thin layer chromatography; antioxidant activity was determined by the DPPH inhibition assay. In phytochemical screening there was a greater concentration of phenolic compounds and antioxidant activity was at 25 and $35 \mu \mathrm{g} / \mathrm{mL}$ respectively, with an IC 50 of $12.82 \mu \mathrm{g} / \mathrm{mL}$. In conclusion, the standardized hydroalcoholic extract from Juglans neotropica Diels leaves fulfilled the quality parameters, and showed high antioxidant activity.

\footnotetext{
${ }^{a}$ Laboratorio de Farmacognosia y Medicina Tradicional. Instituto de Investigación en Ciencias Farmacéuticas y Recursos Naturales "Juan de Dios Guevara". Facultad de Farmacia y Bioquímica. Universidad Nacional Mayor de San Marcos. Jr. Puno 1002. Jardín Botánico. Lima. *phurtado16@hotmail.com

๖. Instituto de Investigación de Ciencias Químicas. Facultad de Química e Ingeniería Química. Universidad Nacional Mayor de San Marcos.
} 
Key words: Juglans neotropica Diels, peruvian walnut, standardized extract, phytochemical screening, antioxidant activity

\section{INTRODUCCIÓN}

Juglans neotropica Diels "nogal peruano" es un árbol grande, de hasta $35 \mathrm{~m}$ de altura y de $30 \mathrm{~cm}$ a $120 \mathrm{~cm}$ de diámetro. Tiene el tronco recto y cilíndrico. En el Perú, está distribuido en Amazonas, Cajamarca, Cusco, Huancavelica, Junín, La Libertad, Lambayeque y Pasco. El rango de distribución altitudinal oscila entre 500 y 3300 msnm (ceja de selva, en zonas de bosque húmedo premontano y montano). Se observa en los bosques secundarios tardíos y en el bosque maduro. ${ }^{1}$

Las hojas son consideradas fuente de compuestos saludables y han sido usadas ampliamente en la medicina tradicional para el tratamiento de dermatitis, insuficiencia venosa y úlceras; y posee propiedades antidiarreica, antihelmíntica, antiséptica, antibacteriana, astringente, antioxidante, antifúngico, hipoglicémica y antiproliferativa. ${ }^{2-6}$

En el Perú las hojas se usan como astringente, en lavados uterinos, para lavar heridas, con leche para tratar la tos y como cataplasma para las articulaciones hinchadas. El cocimiento del fruto fresco como enjuagatorio para las llagas y úlceras en la cavidad bucal. ${ }^{7,8}$

El empleo de extractos estandarizados a partir de plantas medicinales como materias primas en la industria farmacéutica, representa un área de franca expansión, que adquiere una importancia cada vez mayor, porque facilita una mejor caracterización analítica y permite que se cumplan de manera eficaz los requisitos de calidad, efectividad y seguridad exigidos para cualquier medicamento moderno. ${ }^{9}$

El objetivo de la presente investigación fue: evaluar la actividad antioxidante del extracto hidroalcohólico estandarizado de las hojas de Juglans neotropica Diels "nogal peruano".

\section{PARTE EXPERIMENTAL}

Muestra: La muestra vegetal fue recolectada durante el mes de junio del 2013 en el distrito de Huandoval, provincia de Pallasca, Región Ancash a 3035 m.s.n.m y clasificada taxonómicamente en el Museo de Historia Natural de la Universidad Nacional Mayor de San Marcos por el biólogo Mario Benavente.

Preparación del extracto hidroalcohólico: $230 \mathrm{~g}$ de las hojas fueron maceradas en $1000 \mathrm{~mL}$ de solución hidroalcohólica de etanol: agua (7:3) durante 14 días en un frasco de color ámbar a temperatura ambiente con agitación constante durante los primeros siete días. La solución se filtró con papel filtro; el extracto se colocó en estufa MEMMERT a $40^{\circ} \mathrm{C}$ para eliminar el etanol. El extracto seco se conservó en un frasco de color ámbar en refrigeración, hasta el momento de su utilización.

Análisis de parámetros de estandarización: Se determinó la humedad por el método gravimétrico y los siguientes parámetros: olor, color, aspecto, $\mathrm{pH}$, densidad relativa e índice 
de refracción. Luego se realizó la marcha de solubilidad, tamizaje fitoquímico y cromatografía en capa fina.

La determinación de la humedad se hizo pesando la muestra de hojas frescas en balanza analítica OHAUS y secándola hasta peso constante en estufa MEMMERT a $105^{\circ} \mathrm{C}$ hasta que la diferencia de peso entre las 2 últimas pesadas se encuentren dentro de la exactitud requerida $(\leq 0,2 \mathrm{mg})$ lo que indica que se alcanzó el peso constante. ${ }^{9}$

El tamizaje fitoquímico se realizó mediante pruebas fisicoquímicas de caracterización, mediante cambios de coloración o formación de precipitados. ${ }^{10}$ Se desarrolló en el Laboratorio de Farmacognosia de la Facultad de Farmacia y Bioquímica de la Universidad Nacional Mayor de San Marcos.

Se usó la cromatografía en capa fina, para identificar las concentraciones de taninos y flavonoides, usando como fase estacionaria sílica gel 60 F254 y como fase móvil 1-butanol: ácido acético: agua (BAW) (4:1:5); los reveladores usados fueron: tricloruro férrico 1\% para taninos y tricloruro de aluminio para flavonoides. Los estándares usados para taninos fueron: ácido tánico y ácido gálico; para flavonoides, quercetina y rutina. En el caso de los flavonoides, se observó la placa cromatográfica a luz UV de $365 \mathrm{~nm}$ antes y después del revelado.

Determinación de la actividad antioxidante: La actividad antioxidante del extracto hidroalcohólico se evaluó mediante la capacidad captadora del radical DPPH11. Un volumen de 1,6 mL de una solución metanólica de DPPH $2 \mathrm{mg} \%$ se mezcló con 0,8 mL del extracto seco disuelto en etanol $70^{\circ}$; la mezcla se dejó en reposo y en ausencia de luz durante 30 minutos. Transcurrido este tiempo se leyó la absorbancia a $517 \mathrm{~nm}$ en un espectrofotómetro SPECTROQUANT® Pharo 300 de Merck. El extracto seco se analizó por triplicado. El extracto fue evaluado a diferentes concentraciones de $5,15,25$ y $35 \mu \mathrm{g} / \mathrm{mL}$ preparados a partir de una solución de $300 \mu \mathrm{g}$ de extracto seco $/ \mathrm{mL}$ de etanol $70^{\circ}$. Se utilizó Trolox (ácido 6-hidroxi-2,5,7,8-tetrametilcromo-2-carboxílico) como estándar de referencia. Los resultados fueron convertidos a porcentaje de captación de radicales libres y expresados como capacidad antioxidante en mg equivalentes Trolox/g de extracto seco. (TEAC)

\section{Determinación de humedad}

\section{RESULTADOS Y DISCUSIÓN}

Tabla 1. Primera pesada de las hojas de Juglans neotropica Diels

\begin{tabular}{ccccc}
\hline $\mathrm{N}^{\circ}$ & $\begin{array}{c}\text { Pesafiltro vacío } \\
(\mathrm{g})\end{array}$ & $\begin{array}{c}\text { Muestra } \\
\text { húmeda }(\mathrm{g})\end{array}$ & $\begin{array}{c}\text { Pesafiltro }+ \\
\text { muestra seca }\end{array}$ & \% Humedad \\
\hline 1 & 25,0677 & 3,0100 & 26,4382 & $45,53 \%$ \\
2 & 25,1142 & 3,0044 & 26,4513 & $44,50 \%$ \\
3 & 22,5197 & 3,0412 & 23,8506 & $43,76 \%$ \\
\hline
\end{tabular}


Tabla 2. Segunda pesada de las hojas de Juglans neotropica Diels

\begin{tabular}{|c|c|c|c|c|}
\hline $\mathrm{N}^{\circ}$ & $\begin{array}{l}\text { Pesafiltro vacío } \\
\text { (g) }\end{array}$ & $\begin{array}{c}\text { Muestra } \\
\text { húmeda }(\mathrm{g})\end{array}$ & $\begin{array}{l}\text { Pesafiltro }+ \\
\text { muestra seca }\end{array}$ & $\%$ Humedad \\
\hline 1 & 25,0677 & 3,0100 & 26,4373 & $45,50 \%$ \\
\hline 2 & 25,1142 & 3,0044 & 26,4504 & $44,47 \%$ \\
\hline 3 & 22,5197 & 3,0412 & 23,8496 & $43,72 \%$ \\
\hline
\end{tabular}

$\%$ de Humedad de hojas frescas de nogal: 44,56 $\pm 0,02 \%$

El porcentaje de humedad de las hojas frescas está dentro de los valores normales para hojas $(20-75 \%) .^{12}$

\section{Determinación de parámetros fisicoquímicos}

Tabla 3. Parámetros fisicoquímicos del extracto hidroalcohólico de las hojas de Juglans neotropica Diels

\begin{tabular}{ll}
\hline Propiedades & Extracto al 2\% \\
\hline Olor & Sui generis \\
Color & Marrón oscuro \\
Aspecto & Líquido \\
$\mathrm{pH}$ & 6,5 \\
Densidad relativa & 0,6052 \\
Índice de refracción $\left(\mathrm{T}: 22,3^{\circ} \mathrm{C}\right)$ & $1,365 / 22^{\circ}$ Brix \\
\hline
\end{tabular}

\section{Marcha de solubilidad}

En la marcha de solubilidad del extracto hidroalcohólico de hojas de Juglans neotropica Diels se evidenció que es más soluble en solventes polares (tabla 4).

Tabla 4. Marcha de solubilidad de las hojas de Juglans neotropica Diels

\begin{tabular}{ll}
\hline Solvente & Resultado \\
\hline Agua destilada & ++ \\
Etanol $96^{\circ}$ & ++ \\
Etanol $70^{\circ}$ & +++ \\
Éter etílico & +++ \\
Metanol & + \\
Hexano & + \\
Acetato de etilo & ++ \\
Cloroformo & +++ \\
Diclorometano & +++ \\
\hline
\end{tabular}

Leyenda: +: Poco soluble, ++: Medianamente soluble, +++ : Soluble, ++++ : Muy soluble 


\section{Tamizaje fitoquímico}

En el tamizaje fitoquímico se identificó metabolitos primarios y secundarios (tabla 5). Se observó carbohidratos, azúcares reductores, compuestos fenólicos como flavonoides y taninos, esteroides, triterpenos, saponinas y alcaloides. En un estudio sobre la actividad cicatrizante del extracto hidroalcohólico de las hojas de Juglans neotropica Diels, se demostró la presencia de aminoácidos, flavonoides, taninos y saponinas como componentes mayoritarios, mientras que los compuestos fenólicos y lactonas se encontraban en menor cantidad. ${ }^{13}$

Tabla 5. Tamizaje fitoquímico de las hojas de Juglans neotropica Diels

\begin{tabular}{lll}
\hline Metabolito & Reacción & Resultado \\
Carbohidratos & Molish & ++ \\
& Fehling & +++ \\
Azúcares reductores & Benedict & ++ \\
& Trommer & +++ \\
Compuestos fenólicos & $\mathrm{FeCl}_{3}$ & ++++ \\
Taninos & Gelatina & ++ \\
Antraquinonas & Borntrager & ++ \\
Aminoácidos libres & Ninhidrina & - \\
Esteroides & Liebermann & +++ \\
Triterpenos & Burchard & \\
Flavonoides & Shinoda & + \\
Saponinas & Espuma & + \\
& Bertrand & + \\
& Bouchardart & + \\
Alcaloides & Dragendorff & + \\
& Mayer & + \\
& Popoff & + \\
\hline
\end{tabular}

Leyenda: - (Ausencia), + (Trazas), ++ (Positivo), $+++($ Abundante $),++++($ Muy abundante $)$

\section{Cromatografía en capa fina}

La cromatografía en capa fina de los compuestos fenólicos reveló que el extracto hidroalcohólico de hojas de Juglans neotropica Diels, en el caso de taninos, las concentraciones de ácido tánico y ácido gálico están cercanas $(\mathrm{Rf}=0,78$ y $\mathrm{Rf}=0,80$ respectivamente) (figura 1$)$; en el caso de flavonoides, se evidenció mayor concentración de quercetina $(\mathrm{Rf}=0,86)$ después del revelado sin luz UV de 365 nm (figura 2) y a la luz UV (figura 3).

En el caso de taninos, se usó los estándares de ácido tánico y ácido gálico; para flavonoides, quercetina y rutina. El extracto hidroalcohólico demostró mayor presencia de ácido tánico 
con revelador tricloruro férrico y quercetina con revelador tricloruro de aluminio. Para los taninos, la muestra recorrió la misma distancia que el ácido tánico y una distancia cercana al ácido gálico, lo que confirma que el extracto hidroalcohólico de las hojas de Juglans neotropica Diels posee los dos tipos de taninos.

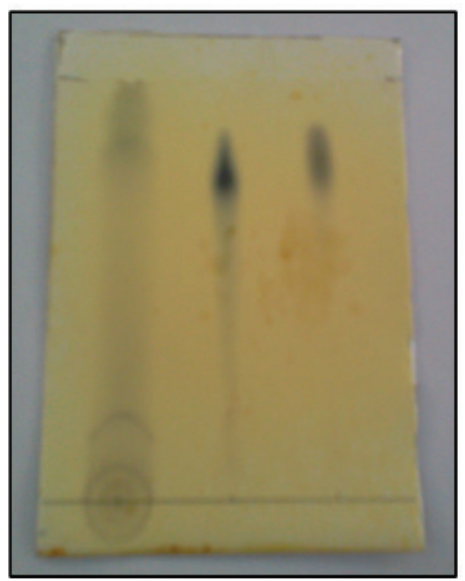

Figura 1. Cromatograma de taninos

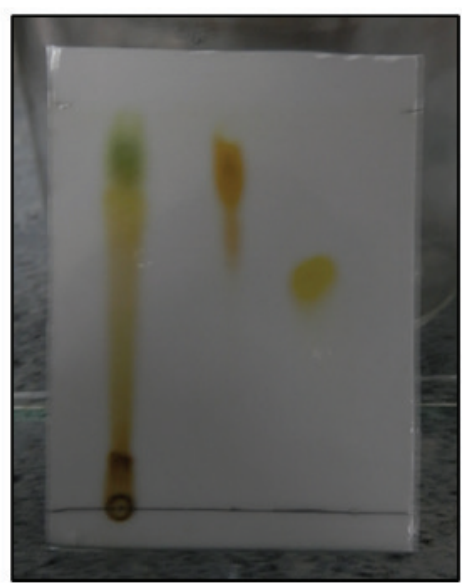

Figura 2. Cromatograma de flavonoides

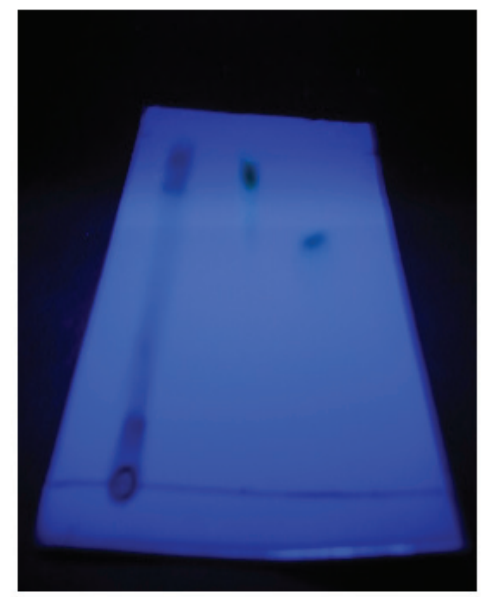

Figura 3. Cromatograma de flavonoides a la luz UV $365 \mathrm{~nm}$ 


\section{Actividad antioxidante}

El extracto hidroalcohólico de las hojas de Juglans neotropica Diels exhibió alta capacidad antioxidante a 25 y $35 \mu \mathrm{g} / \mathrm{mL}$ con un porcentaje de captación de 89,89 y 92,47 $\%$ respectivamente como se presenta en la tabla 6 . Otros autores ${ }^{4}$ analizaron la actividad antioxidante de catorce variedades de hojas de Juglans regia, donde obtuvieron porcentajes de captación de 81,9 a $93,5 \%$.

Tabla 6. Porcentaje de captación de radicales libres

\begin{tabular}{cccc}
\hline $\begin{array}{c}\text { Concentraciones } \\
(\mu \mathrm{g} / \mathrm{mL})\end{array}$ & $\begin{array}{c}\text { Promedio } \\
\text { absorbancia }\end{array}$ & $\begin{array}{c}\text { \% de } \\
\text { Captación RL }\end{array}$ & $\begin{array}{c}\text { IC 50 } \\
(\mu \mathrm{g} / \mathrm{mL})\end{array}$ \\
\hline 5 & 0,255 & $20,95 \pm 0,78$ & \\
15 & 0,112 & $65,33 \pm 1,11$ & $12,82 \pm 0,220$ \\
25 & 0,033 & $89,89 \pm 0,47$ & \\
35 & 0,024 & $92,47 \pm 0,18$ & \\
\hline
\end{tabular}

Para el ensayo de DPPH, se calculó el IC 50 del trolox $(2,62 \mu \mathrm{g} / \mathrm{mL})$ y del extracto seco (tabla 6). Un valor bajo de IC 50 indica alto poder antioxidante. El trolox, como estándar, siempre exhibirá un menor valor de IC 50 a comparación del extracto seco, que en este caso fue de $12,82 \mu \mathrm{g} / \mathrm{mL}$. Doroteo et a $\mathrm{l}^{14}$ evaluaron la capacidad antioxidante de seis plantas peruanas, entre ellas la corteza de Uncaria tomentosa, que tuvo un IC 50 de 12,05 $\mu \mathrm{g} / \mathrm{mL} 14$; Solanilla et al evaluaron el potencial antioxidante del extracto hidroalcohólico de las hojas de Mollinedia racemosa, donde el IC 50 fue de $14,59 \mu \mathrm{g} / \mathrm{mL} 15$, lo que significa que tienen una actividad antioxidante cercana a las hojas de Juglans neotropica Diels. En el estudio de Rahimipanah et $a 1^{16}$ se usó las cáscaras de Juglans regia para evaluar la capacidad antioxidante, que dio como resultado un IC 50 de $0,18 \mathrm{mg} / \mathrm{mL} .{ }^{16} \mathrm{La}$ diferencia entre este resultado y el obtenido en este estudio se debería a que usaron diferentes órganos de la planta para la determinación de la actividad antioxidante. La capacidad antioxidante equivalente en trolox o TEAC del extracto hidroalcohólico de nogal fue de $255,07 \mathrm{mg}$ equivalentes Trolox/g de extracto seco.

\section{CONCLUSIONES}

El extracto hidroalcohólico estandarizado de hojas de Juglans neotropica Diels cumplió con los parámetros de calidad de olor, color, $\mathrm{pH}$, densidad relativa e índice de refracción, humedad, solubilidad, tamizaje fitoquímico y cromatografía en capa fina; también presentó alta actividad antioxidante, con 92,47\% de captación de radical DPPH a $35 \mu \mathrm{g} / \mathrm{mL}$.

\section{AGRADECIMIENTO}

Agradecimiento al Instituto de Investigación en Ciencias Farmacéuticas y Recursos Naturales "Juan de Dios Guevara" de la Facultad de Farmacia y Bioquímica por el apoyo brindado durante la realización de esta investigación. 


\section{BIBLIOGRAFÍA}

1. Reynel C, Marcelo J. Árboles de los Ecosistemas Forestales Andinos. Manual de Identificación de Especies. Serie Investigación y Sistematización $\mathrm{N}^{\circ} 9$. Programa Regional ECOBONA - INTERCOOPERATION. Lima. 2009.

2. Eidi A, Moghadam JZ, Mortazavi P, Rezazadeh S, Olamafar S. Hepatoprotective effects of Juglans regia extract against $\mathrm{CC}_{14}$-induced oxidative damage in rats. Pharm Biol. 2013; 51 (5): 558-565.

3. Nogal. [Internet]. Ecotintes. [accesada el 20 de febrero del 2014]. Disponible en: http:// www.ecotintes.com/content/es/nogal

4. Cosmulescu S, Trandafir I. Anti-oxidant activities and total phenolic contents of leaf extracts from 14 cultivars of walnut (Juglans regia L.). J Hortic Sci Biotechnol. 2012; 87 (5): 504-508.

5. Carvalho M, Ferrreira PJ, Mendes VS, Silva R, Pereira JA, Jerónimo C et al. Human cancer cell antiproliferative and antioxidant activities of Juglans regia L. Food Chem Toxicol. 2010; 48: 441-447.

6. Santos-Filho SD, Leite Diniz C, Santos do Carmo F, de Souza da Fonseca A, BernardoFilho M. Influence of an Extract of Juglans regia on the Growht of Escherichia coli, on the Electrophoretic Profile of Plasmid DNA and on the Radiolabeling of Blood Constituents. Braz arch biol technol. 2008, 51: 163-168.

7. Gibaja S. Pigmentos naturales quinónicos. Fondo Editorial UNMSM Lima, 1998.

8. Brack Egg A. Diccionario Enciclopédico de Plantas Útiles en el Perú. Ecología y Desarrollo. Programa de las Naciones Unidas para el Desarrollo. 1999.

9. Salomón S, López O, González ML. Desarrollo de una tecnología para la obtención de extracto acuoso de Momordica charantia L. Rev Cubana Plant Med. 2011; 16 (4): 304312.

10. Gorriti A, Córdova A, Jurado B, Ortega EC, Retuerto MG. Manual de Laboratorio de Farmacognosia I. Cátedra de Farmacognosia y Medicina Tradicional. UNMSM. 2013.

11. Ramos E, Castañeda B, Ibáñez L. Evaluación de la capacidad antioxidante de plantas medicinales peruanas nativas e introducidas. Rev Acad Peru Salud. 2008; 15 (1): 42-46.

12. Sharapin N. Fundamentos de tecnología de productos fitoterapéuticos. Serie Ciencia y Tecnología. Convenio Andrés Bello, Bogotá, Colombia. 2000.

13. Juro S, Flores V, Mendoza Y, del Carpio C. Efecto cicatrizante de las diferentes formas 
farmacéuticas tópicas elaboradas con el extracto hidroalcohólico de Juglans neotropica Diels "nogal” en ratones albinos. Folia dermatol Perú. 2010; 21 (1): 19-24.

14. Doroteo VH, Díaz C, Terry C, Rojas R. Compuestos fenólicos y actividad antioxidante in vitro de 6 plantas peruanas. Rev Soc Quím Perú. 2013; 79 (1): 13-20

15. Solanilla JF, Lombo O, Murillo E, Méndez JJ. Valoración del potencial antioxidante de Mollinedia racemosa (romadizo). Rev Cubana Plant Med. 2011; 16 (2): 151-163.

16. Rahimipanah M, Harmedi M, Mirzapour M. Antioxidant activity and phenolic contents of Persian walnut (Juglans regia L.) green husk extract. Afr J Food Sci Technol. 2010; 1(4): 105-111. 